\begin{tabular}{|l|l|}
\hline Postprint Version & 1.0 \\
\hline Journal website & http://www.informaworld.com/smpp/content $\sim$ content=a934987733 db=all \\
\hline Pubmed link & http://www.ncbi.nlm.nih.gov/pubmed/21409709 \\
\hline DOI & $10.1080 / 00224499.2011 .555929$ \\
\hline
\end{tabular}

\title{
The Psychological Measurement of Childhood Sexual Development in Western Societies: Methodological Challenges
}

\author{
HANNEKE DE GRAAF ${ }^{1}$
}

JANY RADEMAKERS ${ }^{2}$

${ }^{1}$ Rutgers WPF

${ }^{2}$ NIVEL, The Netherlands Institute for Health Services Research

Children can display sexual behavior or have sexual experiences. Different psychological research methods are available for studying these kinds of behaviors and feelings, such as interviewing or observing children (direct methods), asking adolescents or adults to retrospectively report their childhood memories or using intermediaries to observe children (indirect methods).

Each of these methods has its own advantages and limitations. Based on a review of the literature, this work answers three questions: (a) What research methods are generally used to study childhood sexual development? (b) What insight do these methods give into the sexual behaviors or feelings of children? and (c) What are the advantages and limitations of each of these research methods in this research domain? Almost all studies on childhood sexual behavior and feelings use either observational or retrospective methods. In both types of studies, only behavior that is considered to be sexual from an adult perspective is reported. To gain insight into the child's perspective, one has to rely on methods other than observations or retrospective research, such as interviews with children that match their developmental limitations and competencies.

Most research on childhood sexuality focuses on sexual abuse. Of all publications in the PsychINFO, Medline, and Social SciSearch databases that combine child(ren) and sexual(ity) in their titles, only 1\% do not treat sexual behavior of children as either a part or a consequence of sexual abuse. Because of the negative consequences that sexual abuse can have for its victims, it is understandable that people fear sexual abuse and that sexual abuse has been extensively studied. The strong focus on sexual abuse, however, can have some serious negative side effects. One possible effect is that children's sexual behaviors or feelings are often assumed to be atypical and signs of sexual abuse (Bancroft, 2003). Children who have not been sexually abused, however, can also display sexual behaviors or feelings (De Graaf \& Rademakers, 2006). To differentiate normative childhood sexual experiences from abuse, it is important to know what kinds of experiences can be expected of children. This will help parents and other educators to decide how to respond to these behaviors and feelings. 
Childhood sexuality has been studied by researchers from various disciplines (e.g., psychology, sociology, pediatrics, anthropology, biology, history, and law; Frayser, 1995). There are studies that focus on the evolutionary, sociocultural, historical, or developmental context of childhood sexuality. Within this broader field of sex research, this review chooses a developmental psychological perspective. A broad definition of childhood sexuality is used in this review, encompassing behaviors like showing, touching, naming, and stimulation of genitals; and the feelings and cognitions accompanying these behaviors. In his model of sexual development, Bancroft (2009, p. 146) distinguished three different “strands"': gender identity; sexual response; and the capacity for close, dyadic relationships. Although we agree that gender identity development is an important part of sexual development (for a review, see Martin \& Ruble, 2010), this review focuses on the last two strands of Bancroft's model because the paucity of knowledge stands out most with regard to these strands (Frayser, 1995).

Although information about what behaviors or feelings are typical during childhood is important, this knowledge is not sufficient to be able to decide whether or not to intervene. Unusual behaviors are not necessarily problematic. Presumably, from a developmental perspective, it is especially important to guide or correct behaviors that elicit negative feelings (e.g., fear or disgust). Experiences that are negatively evaluated appear to associate more often with problems in adult functioning (Finkelhor, 1981; Kilpatrick, 1986).

Research where the feelings surrounding sexual experiences during childhood are not taken into account usually does not find any long-term effects (Okami, Olmstead, \& Abramson, 1997). To evaluate the sexual experiences of children, it is essential to have insight into the child's own perspective on these behaviors and feelings (viz. the subjective perceptions, interpretations, cognitions, and emotions of the child). This knowledge should be based on solid empirical evidence.

An earlier review of empirical knowledge of childhood sexuality revealed that studies of childhood sexuality outside of sexual abuse are scarce (De Graaf \& Rademakers, 2006). This gap in knowledge stands out relative to other research on child development and human sexuality (Frayser, 1995). Several factors impede the study of childhood sexuality. Memory, language, and social development affect the methodologies that are available for psychological research with children of different ages and the validity and reliability of the results. The cultural taboo around (child) sexuality, however, makes this research topic more sensitive than other areas of child development. Because research methods are closely intertwined with the results that are potentially generated, gaps in knowledge on childhood sexuality are at least partly related to limitations in the methodologies that are used.

Based on a systematic review of the literature, we answer three questions: (a) What research methods are generally used to study childhood sexual development? (b) What insight do these methods give into the sexual behaviors or feelings of children? and (c) What are the advantages and limitations of each of these research methods in this research domain? The purpose of this review is to identify methodological shortcomings of previous research on childhood sexual development in order to suggest alternative research methods, which are potentially more appropriate for gaining insight into the child's perspective. The findings of this review can be of practical use to researchers and so contribute to generating more reliable and valid knowledge of childhood sexual development, which subsequently can be used by educators.

\section{[TABLE 1]}

\section{METHOD}

\section{Retrieval}

To identify relevant studies, we searched the following databases: PsychINFO, Medline, Social SciSearch, and the database of the library of the Rutgers Nisso Groep (The Netherlands Expert Center on Sexuality).

We used variations of sexual development terms (viz.

sexual development, psychosexual development, psychosexual behavior, sexuality, or sexual attitudes) and variations of childhood terms (viz. [early] childhood development, age differences, child attitudes, early experience, developmental stages, elementary school students, preschool students, childhood play behavior, 
or childhood play development). In addition, we used reference lists and cited references of selected publications.

Inclusion and Exclusion Criteria For inclusion in the review, studies had to (a) empirically examine either sexual behaviors (solitary, as well as interpersonal), sexual feelings (e.g., feelings about being naked, touched, or cuddled; being in love; or sexual excitement), or sexual cognitions (e.g., sexual knowledge or attitudes); (b) focus on children (between zero and 12 years of age); (c) be published in peer-reviewed journals or books, (d) be carried out in North America, Western Europe, Australia, or New Zealand; and (e) be published between January 1980 and December 2009. Studies were excluded if they focused on child sexual abuse (i.e., sexual activity perpetrated against the child by threat, force, intimidation, or manipulation). The same criteria were applied to studies of the biological and environmental determinants of sexual development and research on long-term consequences of childhood sexual experiences.

Characteristics of the final selection of the 44 studies that met the inclusion and exclusion criteria can be found in Table 1.

\section{RESULTS}

\section{Methods Used in Research on Childhood Sexuality}

An earlier review of 25 empirical studies of childhood sexuality published between 1985 and 2003 showed that most studies of childhood sexuality do not question or observe children (direct methods), but question intermediaries about their observations or adolescents or adults about their childhood memories (indirect methods). A review of recently published literature reveals few things have changed in this regard (De Graaf \& Rademakers, 2009). Table 2 schematically shows the research methods used by the 44 studies included in this review. These methods and their results are summarized here, divided into four different developmental phases: infants and toddlers (aged zero to two), preschoolers (aged three to five), middle childhood (aged six to nine), and late childhood (aged 10-12).

\section{Infants and toddlers.}

Only two of the 44 selected studies examined the sexual behavior of infants and toddlers (aged zero to one). Galenson (1990) observed genital stimulation and accompanying facial expressions of very young children (aged zero to two) at day care centers. She found that boys of six to eight months of age and girls of eight to 11 months of age discovered their genitals by touching them. Genital touching becomes more direct toward the end of the first year, when locomotion is sufficiently developed. From 15 to 19 months of age, rhythmic stimulation of the genitals can be present (e.g., manual or by pressing the thighs together or rubbing against something or someone).

These behaviors are sometimes accompanied by facial expressions of pleasure, flushing, rapid respiration, or perspiration.

Schuhrke (2000) asked parents (usually mothers) to record all manifestations of their child's curiosity about their own and other people's bodies during the second year of life in a diary. These parents were interviewed about their observations. Almost all of these children showed interest in their own and especially their parents' genitals by touching, naming, or looking at them. Three other studies also asked parents or child care providers of infants and toddlers to report on the sexual behaviors of these children, but these studies did not present their results separately for different age groups (Lopez Sanchez, Del Campo, \& Guijo, 2002; Phipps-Yonas, Yonas, Turner, \& Kauper, 1993; Sandfort \& Cohen- Kettenis, 2000).

\section{[TABLE 2]}

\section{Preschoolers.}

Research on sexual behaviors, feelings, or cognitions of preschoolers (aged two to five) can be roughly divided into two groups: observations of sexual behavior by intermediaries and interviews with children themselves to test their knowledge of sexuality. 
In 17 out of the 44 studies included in this review, mothers or other intermediaries (e.g., day care personnel and teachers) were asked to observe and report the sexual behaviors of their own children or the children in their care. All of these studies included preschoolers.

In most of these studies, the intermediaries reported their findings by means of a paper-and-pencil survey (Friedrich, Fisher, Broughton, Houston, \& Shafran, 1998; Friedrich, Grambsch, Broughton, Kuiper, \& Beilke, 1991; Friedrich, Sandfort, Oostveen, \& Cohen- Kettenis, 2000; Larsson \& Svedin, 2002b; Lindblad, Gustafsson, Larsson, \& Lundin, 1995; Lopez Sanchez et al., 2002; Oostveen, Meulmeester, \& CohenKettenis, 1994; Phipps-Yonas et al., 1993; Rosenfeld, Bailey, Siegel, \& Bailey, 1986; Sandfort \& CohenKettenis, 2000; Sandnabba, Santtila, Wanna"s, \& Krook, 2003; Schoentjes, Deboutte, \& Friedrich, 1999). Most of these studies used (a translation of) a validated instrument: the Child Sexual Behavior Checklist (Friedrich et al., 1998; Friedrich et al., 1991; Friedrich et al., 2000; Larsson \& Svedin, 2002b; Oostveen et al., 1994; Sandfort \& Cohen-Kettenis, 2000; Sandnabba et al., 2003; Schoentjes et al., 1999). Four studies did not use an existent, validated instrument (Lindblad et al., 1995; Lopez Sanchez et al., 2002; PhippsYonas et al., 1993; Rosenfeld et al., 1986). In three studies, the intermediaries were interviewed about their observations (Davies, Glaser, \& Ska $r$, 1981; Thigpen, 2009). Most of these observations were retrospectively reported. Only Kaeser, DiSalvo, and Moglia (2000) asked preschool teachers to record their observations in a diary, which was subsequently sent to the researchers.

These studies show that during preschool years, touching of genitals at home and touching of the mother's or other women's breasts are the most frequently observed sexual behaviors. Looking at people when they are nude is also common. Preschoolers are not very aware of sexual taboos yet, as they are frequently found to touch their genitals in public (Friedrich et al., 1998; Larsson \& Svedin, 2002a; Lopez Sanchez et al., 2002; Sandfort \& Cohen-Kettenis, 2000; Schoentjes et al., 1999; Thigpen, 2009).

In three studies, preschoolers were directly questioned about their knowledge of sexuality: for example, knowledge of the proper names for genitalia, the differences between boys and girls, and reproduction (Brilleslijper- Kater \& Baartman, 2000; Gordon, Schroeder, \& Abrams, 1990; Volbert, 2000). In all of these studies, drawings were used to clarify the questions to the children. These studies show that between the ages of two and five, children often gain knowledge of genital differences, gender identity, sexual body parts, and (nonsexual) functions of the genitals. Knowledge of pregnancy, birth, reproduction, and especially adult sexual behavior is still limited by the age of five.

\section{Middle childhood.}

In research on sexuality of children six years and older, three types of methodologies can be distinguished: observational studies, retrospective studies, and interviews with children. Eight of the observational studies mentioned in the section about preschoolers also included elementary school children (Friedrich et al., 1998; Friedrich et al., 1991; Lopez Sanchez et al., 2002; Rosenfeld et al., 1986; Sandfort \& Cohen-Kettenis, 2000; Schoentjes et al., 1999; Schuhrke, 2000; Thigpen, 2009). All of these studies used parental (maternal) observations, but one of them (Lopez Sanchez et al., 2002) also used teacher observations. The behaviors observed during middle childhood are roughly the same as those observed during preschool years, but the frequency of reported behaviors usually declines with age if this method is used (Friedrich et al., 1998; Lopez Sanchez et al., 2002). Some behaviors, however, are more typical for middle childhood than for preschoolers: playing doctor, asking questions about sexuality, looking at nude pictures, drawing sexual parts, talking about sex acts, and knowledge of sexuality (Friedrich et al., 1998; Sandfort \& CohenKettenis, 2000).

In 11 of the 44 selected studies, adolescents or adults (usually college students) retrospectively reported on their childhood sexual experiences (solitary and interpersonal) and feelings surrounding these experiences.

Recalled experiences, in general, did not go back beyond the age of six, but all extended into late childhood, and some even into adolescence. In 10 of these studies, participants were asked to fill out a questionnaire about their childhood sexual experiences (Bancroft et al., 2003; Finkelhor, 1981; Goldman \& Goldman, 1988; Haugaard, 1996; Haugaard \& Tilly, 1988; Lamb \& Coakley, 1993; Larsson \& Svedin, 2002a; Lopez Sanchez et al., 2002; Nelson, 1986; Reynolds, Herbenick, \& Bancroft, 2003). Most of these studies used paper-andpencil questionnaires; only Bancroft et al. and Reynolds et al. used computerassisted self-interviews. None of these studies used an instrument that was validated for retrospective research. Lamb (2004) obtained childhood memories by means of an interview, without using prompts or cues to facilitate recall. 
Contrary to the results of observational studies, the percentages of retrospectively reported behaviors generally increase with age. The only study that distinguished middle childhood from late childhood found that merely showing and touching of genitals were more frequently reported for middle childhood, compared to late childhood.

The exploration of genitals, looking at nude people or pictures, sexual talk, and kissing and hugging were common behaviors within this age group (Larsson \& Svedin, 2002a). Interpersonal sexual experiences during middle childhood are often embedded in a fictitious context, such as "doctors and nurses" or "mothers and fathers”' (Goldman \& Goldman, 1988; Lamb \& Coakley, 1993).

Interviews with children aged six to nine usually focus on feelings of (being in) love (Hatfield, Schmitz, Cornelius, \& Rapson, 1988; Rademakers, Laan, \& Straver, 2003) or sexual knowledge (Berends \& Caron, 1994; Goldman \& Goldman, 1982). Rademakers et al. also asked sevenand eight-year-olds which parts of their bodies they experienced as " "pleasant" or "exciting." Interview studies show that knowledge of pregnancy, birth, reproduction, and adult sexual behavior generally increases during middle childhood, depending on the country where a study is conducted. Six- to nine-year-olds can be aware that a man and a woman need to have intercourse to conceive a child, but most of them do not know any other reason to have intercourse (Goldman \& Goldman, 1982).

At this age, children rarely mention the genitals as the most pleasant or exciting parts of their body. Furthermore, many children fall in love for the first time during middle childhood (Rademakers et al., 2003).

\section{Late childhood.}

Most of the research methods described earlier have also been applied to children aged 10 to 12 . All observational studies that examined middle childhood also included parents of older children in their sample, and all retrospective methods pertained to both middle and late childhood. Moreover, children in this age group were usually interviewed on an individual basis, but sometimes in group settings.

Knowledge of sexuality is again one of the topics here, but values and attitudes, sexual interests, and sexual behaviors were also studied by means of interviews in this age group (Goldman \& Goldman, 1982; Halstead \& Waite, 2001; O’Sullivan \& Meyer-Bahlberg, 2003; Ott \& Pfeiffer, 2009; Paikoff, 1995).

This previously described repertoire of research methodologies is expanded with other methodologies for 10- to 12-year-olds. Survey research is possible at this age because reading skills become more developed (Ballester \& Gil, 2006). Another research method uniquely conducted within this age group is the observation of children in the last years of elementary school by the researchers themselves, to investigate how these children talk about sex and romance (Kuik, 2003; Renold, 2005; Thorne \& Luria, 1986). These three studies all supplemented their observations with interviews, individual or in groups. The consistency of the results of the interviews with the results of the observations makes them more reliable. One other study collected and categorized questions that older children had about sexuality-related topics (Campbell \& Campbell, 1986).

In this particular study, questions were gathered by putting a box in the classroom where children could submit questions. Questions about abortion, homosexuality, and masturbation, however, were not allowed, thereby creating bias.

These studies show that during late childhood, almost all children know that sexual intercourse is necessary for reproduction. Many children of this age also know that there can be other reasons for having intercourse, such as enjoyment (more often mentioned by boys) or an expression of love (more often mentioned by girls; Goldman \& Goldman, 1982). Behaviors that are retrospectively more frequently reported for late childhood, compared to middle childhood, are thinking, talking, and dreaming about sex; watching sexually explicit material; and fondling oneself or masturbation to orgasm (Larsson \& Svedin, 2002a). Based on retrospective studies, it is evident that some children experience their first sexual arousal or orgasm before puberty, but due to different samples and definitions of key concepts, it is impossible to say how many children this applies to (Ballester \& Gil, 2006; Bancroft et al., 2003; Goldman \& Goldman, 1988; Larsson \& Svedin, 2002b; Lopez Sanchez et al., 2002).

The observation that stands out most in the reports of parents of 10- to 12-year-olds is that their child is "very interested in the opposite sex" (Friedrich et al., 1998).

Observations of and interviews with children confirm this finding (O’Sullivan \& Meyer-Balhlberg, 2003; Renold, 2005). Based on these studies, however, it is also clear that there are large individual differences. A 
Graaf, H. de, Rademakers, J. The psychological measurement of childhood sexual development in Western societies: methodological challenges. Journal of Sex Research: 2011, 48(2), 118-129

Dutch and an American study both revealed approximately the same three subgroups among 10- to 12-yearolds: a subgroup that was not interested in sexuality at all (or even disliked talking about it), a subgroup that is very interested (but also finds it a bit awkward and makes lots of jokes), and a subgroup that considers sex to be a "'normal”' part of life (Kuik, 2003; Ott \& Pfeiffer, 2009).

\section{Advantages and Limitations of Research Methods Used}

The review of the existing literature described earlier showed that 20 out of 44 studies on childhood sexual behavior and feelings used observational methods, usually by intermediaries. In 11 out of 44 studies, retrospective methods were used. Thirteen out of 44 studies applied more direct methods, particularly interviews, to uncover how children themselves perceive sexuality.

All these research methods have their specific advantages and limitations, which is described in the following section (see Table 3).

\section{Observational methods.}

The developmental capabilities and limitations of the children that are studied restrict the variety of research methods that can be used.

Observational methods are predominantly used in the younger age groups. If sexual behavior of very young children is the focus of attention (e.g., Davies et al., 2000; Friedrich et al., 2000; Galenson, 1990), this is the only method that is used. Before the age of two, children are not able to answer questions because the capacity of combining spoken words is just beginning at this age.

For preschoolers, it is still difficult to answer questions about their own experiences and internal states due to limited retrieval skills, articulation capacities, and vocabularies (Lamb, Hershkowitz, Orbach, \& Esplin, 2008) and an underdeveloped capacity for self-reflection (Piaget \& Inhelder, 1969).

Depending solely on observations, however, has a number of important limitations. The main disadvantage of this method is the limitation of what can be observed-namely, only behavior that occurs in sight of an observer. Many experiences of children occur out of sight of parents and other adults, especially if they involve taboo behaviors, like masturbation or sexual play. This limitation could explain why many reports of childhood sexual behavior decline with age in observational studies (Friedrich et al., 1991; Schoentjes et al., 1999), whereas reports of childhood sexual behavior generally increase with age in retrospective studies (Larsson \& Svedin, 2002a; Lopez Sanchez et al., 2002). As they get older, children learn more and more that these kinds of behaviors are "private," and they will behave accordingly.

This shortcoming of observational research also explains why different settings elicit different observations.

In one study, parents reported more sexual behavior by their children than did preschool teachers, who observed the same children (Larsson \& Svedin, 2002b).

Another disadvantage of this method is that feelings (e.g., sexual arousal) and cognitions (e.g., motivations) are difficult to observe.

Most observational studies employ intermediaries who observe and report the behaviors under study.

The most important advantage of these indirect observations is that they are time-consuming for researchers than performing the observations themselves and, consequently, researchers elicit information from larger samples more easily. However, this method holds a number of limitations too. One of these limitations is that beliefs and attitudes of the observers may affect their perceptions and interpretations of the child's behavior.

This could explain the finding that parents who hold more permissive attitudes toward childhood sexuality report more sexual behaviors of their children, although this could also mean that children in these families actually do display more sexual behaviors (Friedrich et al., 1998; Friedrich et al., 1991; Sandfort \& CohenKettenis, 2000; Schoentjes et al., 1999).

Because the parents involved in these kinds of studies are usually White and highly educated, information of other sociocultural groups is still missing.

There are no studies where each child is observed by more than one intermediary or researcher. There are, therefore, no studies that include inter-observer reliability scores.

Intermediaries generally report their observations by means of a survey. Although the use of a survey enables researchers to closely define childhood sexual behaviors, it also narrows down what can be observed. Davies et al. 
(2000) included both open-ended and direct questions in their questionnaire, which elicited different observations.

For example, the most common behavior mentioned by preschool staff in response to the open-ended question was a child simulating sexual intercourse with another child. Touching, showing, and looking at genitalia, however, were reported much more often than simulated intercourse when direct questions were used. Interviewing the intermediaries about their observations elicits more detailed descriptions of the observed sexual behaviors and feelings than using a survey. Friedrich (2003) stated, for example, that follow-up interviews with parents who observed more unusual sexual behaviors clarified the context of these behaviors, which, in general, normalized the behaviors of their child.

The intermediaries reported their observations retrospectively in most of these studies, so the observations could have been distorted by memory. Memories are richer in content and more accurate when the delay between the experience that should be remembered and data collection is as short as possible (Lamb at al., 2008). However, even observations that are directly recorded (e.g., in diaries) are influenced by the intermediary's perspective. Especially when a clear definition of childhood sexual behavior is lacking, only behavior that is considered to be sexual from the observer's perspective is reported. In one study where it was up to the intermediaries themselves to decide what they considered sexual behavior or not, it was clear there is no general consensus about this. In this particular study, reported behaviors ranged from masturbation and stroking the arm of another child, to looking at pictures of a pregnant woman and talking about urination (Kaeser et al., 2000).

\section{[TABLE 3]}

\section{Retrospective methods.}

In retrospective studies, adolescents or (emerging) adults are questioned about their own childhood sexual experiences. The most important advantage of retrospective studies is that cognitive abilities of the respondents are sufficiently developed for them to answer (fairly) complicated questions.

Furthermore, retrospective research gives the researcher the opportunity to investigate recalled cognitions or emotions. With older samples, an additional advantage is that parental consent is not required.

However, retrospective research also has a number of limitations, which threaten the validity of its results. A key characteristic of retrospective research is that, depending on their age, participants have to think back for at least a few years. Almost all retrospective studies included in this review employed college students as participants, and one study even included women up to 72 years of age (Lamb, 2004). Because all memories are influenced by time, it is very likely that some experiences of these participants were not accurately remembered or not remembered at all. This could explain why the prevalence of childhood sexual play is considerably higher in the one study using adolescents' reports (Lopez Sanchez et al., 2002), compared to (emerging) adults' reports. In addition, it is very difficult for adolescents or adults to recall experiences before the age of five (Newcombe, Bullock Drummey, Fox, Lie, \& Ottinger-Alberts, 2000).

Reports of solitary, as well as mutual, sexual experiences before the age of six are, therefore, very scarce in retrospective studies (Larsson \& Svedin, 2000a), whereas observational studies show a different picture.

Last, but not least, an important limitation of retrospective research is that, although respondents are able to describe their own point of view, this will not be the same as the perspective they had as a child. The meaning of earlier experiences is continuously reevaluated.

It is possible that experiences that did not have a sexual connotation during childhood will get this sexual meaning if they are remembered from an adult sexual perspective, or vice versa. To our knowledge, studies of precisely how the meaning of childhood sexual experiences is exactly reevaluated have not been carried out.

\section{Directly questioning children.}

Directly questioning children enables us to gain insight into the child's perspective, free from observer and memory distortions. 
This review shows that interviewing children about some aspects of sexuality (e.g., knowledge of genitalia and reproduction) is possible from the age of two. One study questioned children aged nine to 14 by means of a survey. A limitation of questioning children by means of a survey is that it is difficult to formulate questions that are both reliable and valid for studying children. Validity is hard to establish. As long as there is no clear consensus about the child's perspective on those behaviors and feelings that adults consider to be sexual, we are left in the dark about how children interpret questions on this subject. In the survey study included in this review, it is not clear whether the instrument used was pretested among this particular age group (Ballester \& Gil, 2006).

Also, in interviews with children it is essential that the instrument matches the child's developmental level (e.g., in choice of words or by the use of pictures or drawings).

A specific advantage of the use of pictures or drawings is that these can elicit additional information about the child's perspective. Very young children, for example, tend to turn a picture of a male and female lying on top of each other around to show the couple in a standing position, indicating that they have no knowledge of sexual intercourse (Brilleslijper-Kater \& Baartman, 2000). Another limitation of this method is that researchers have to overcome a lot of resistance from parents and teachers to be able to interview children about this taboo topic. Finally, just like other research methods, the influence of the interviewer's perspective on the results cannot be ruled out. However, the interviewer can follow certain guidelines to keep this influence as small as possible, which is discussed further below.

\section{DISCUSSION AND DIRECTIONS FOR FUTURE RESEARCH}

This review shows that there is no single best method to study childhood sexual responsiveness and the capacity for close, dyadic relationships. Every research method described here can be valuable, depending on the research questions and the ages of the children that are studied. It is hard to find an alternative method for investigating very young children besides observations.

Brain imaging techniques and other psychophysiological methods would be a possibility for measuring arousal, but we expect that these methods would meet enormous resistance from ethical review boards and funding agencies.

Until we find a way to counter this resistance, we depend on observations for the study of infants and toddlers.

However, observations are less suitable for the study of older children because sexual behavior becomes more hidden with increasing age and is, therefore, less observable.

Retrospective research, on the other hand, is not recommended for studying very young children because it is difficult for adolescents or adults to remember experiences before the age of five and impossible before the age of two due to the phenomenon of early childhood amnesia. Interviewing children, however, is possible from the age of two if questions are very concrete, as from this age, the development of memory, language, and social skills makes it gradually more and more possible for children to answer questions about their own experiences. Although memories of preschoolers can be accurate, they tend to remember less information and provide briefer accounts of their experiences (Lamb et al., 2008). At about seven or eight years of age, children enter what Piaget called the concreteoperational phase (Piaget \& Inhelder, 1969), and language and the capacity for self-reflection have sufficiently developed for children to answer questions about fairly complicated topics.

In addition to the choice of a specific research method, the reliability, validity, and generalizability of each of these methods could be improved by taking certain measures.

In observational research, for example, employing parents or day care personnel to perform these observations has certain disadvantages. Undoubtedly, their attitudes toward childhood sexuality influences the sexual behaviors that are reported; and because every child is observed by only one intermediary, it is impossible to detect the exact influence. It is, therefore, preferable that more than one researcher performs the observations, without the use of intermediaries, so that interrater reliability can be calculated.

To minimize distortions by memory, observations should always be recorded as directly as possible (e.g., by the use of diaries or video recordings). To date, studies that have used diaries are scarce, and video recordings are never used in studies of childhood sexuality.

Although all researchers who intend to study childhood sexuality could expect resistance of funding agencies, ethical committees, schools, or parents, the use of video recordings could amplify these 
objections. Goldman and Goldman (1982) encountered considerable opposition from teachers and parents, which was overcome by patient persuasion and persistence. Less resistance ocurred when the study was included in a project covering a broad range of developmental topics.

If researchers do use intermediaries, it is recommended that they strive for samples that are representative of the general population. The selectiveness of the samples used in previous research limits the generalizability of its results. In addition, because of the important influence of the observer's perspective on the reported behaviors, there has to be consensus about what behavior is considered to be sexual and what behavior is not. Bancroft et al.'s (2009) ideas about the three strands in sexual development could be helpful here. Clear communication of definitions of childhood sexual behavior could enhance interobserver reliability. Prior to assessing the prevalence of masturbation in early childhood, for example, researchers should agree on the definition of masturbation. If this definition encompasses arousal, there has to be consensus about what signs of arousal can be observed. Intermediaries could also be trained to conduct interviews with children to gain insight into the child's feelings about and interpretations of the behavior that is observed.

Some of these recommendations also apply to retrospective research methods. Using a representative sample, instead of the frequently used sample of college students, would also enhance the generalizability of the results of these studies. In addition, a number of measures can be taken to reduce memory bias (Berney \& Blane, 1997). The time lapse between a child's current age and the period that is investigated should be as short as possible. In interviews, recall could be facilitated by constructing a personal timeline or a detailed description of the context of past experiences. In addition, researchers have to take into account which types of information are more easily remembered. Facts are better recalled than attitudes, and emotionally laden events are more often remembered inaccurately. Furthermore, similar to observational methods, clear definitions of the measurements improves the reliability of the results.

The absence of valid instruments for the measurement of childhood sexual experiences is striking. These instruments should be developed, possibly by using the multitrait-multimethod approach to examine construct validity (Campbell \& Fiske, 1959).

There is a risk of circular reasoning in trying to reach consensus about the nature of childhood sexual behavior.

The child's perception of those behaviors and feelings that adults consider to be sexual has to be part of this conceptualization, and it is precisely knowledge of this perspective that is currently missing. Exploratory research (viz. research that uses unstructured techniques to define problems and suggest hypotheses), therefore, has to be the starting point. Moreover, because children are the best sources of information about themselves, we have to look for methods that enable children to express their own experiences, emotions, and cognitions.

Consequently, we have to rely on methods other than observations or retrospective research to gain insight into the child's point of view.

From about three years of age, children are capable of sharing with others what they experienced and, consequently, interviews with children become a possible research method. However, preschoolers have some limitations, for example with regard to retrieval, language and social skills, which need to be taken into account if interviews with this age group are used (Lamb et al., 2008). First, children are not used to being asked questions, apart from questions that test their factual knowledge about a topic. Furthermore, children are unwilling to admit that they do not know an answer.

Before starting the interview, the interviewer should, therefore, clarify what is expected and that it is fine to answer 'I don't know." In addition, the interviewer should practice the interviewing technique by starting with some neutral questions. Younger children generally want to give the "right" answer and are more suggestible.

Interviewers should, therefore, be aware of and be able to distance themselves from their own preconceived notions of childhood sexuality. Open-ended questions are preferable. It should be clear to the child that there are no restrictions to the topics that can be discussed.

Retrieval skills are still limited in preschoolers, and gradually increase with age. Younger children, therefore, need more prompts, preferably by repeating their answers to the first open-ended questions and asking them to tell more about these experiences.

Research methods other than interviews are also conceivable, such as video or audio recordings or detailed descriptions of parent-child conversations about sexuality. The oldest children are also able to 
completequestionnaires but their interpretation of the survey questions should be thoroughly pretested (Blair, 2000).

A survey, however, restricts the range of behaviors and feelings that can be reported. The remarkable gap in knowledge of the use of sexually explicit material among children under age 12 reflects, for example, the absence of questions about the subject. Furthermore, it is very possible that children have certain sexual cognitions and emotions, without being consciously aware of this.

These non-reflective cognitions of children cannot be studied with self-report methods, but would require the development of more sophisticated ways to tap into their "preconscious" information-processing mechanisms.

Future studies should investigate the possibilities of these kinds of methodologies.

Because all of the methods described earlier have their own advantages and limitations, and choosing one method or the other will influence the results, triangulation is recommended. Triangulation is the use and combination of several methods to study the same phenomenon in order to double-check (or triple-check) the results. Some of the studies described in this review used triangulation: They observed children in their classroom, talked to them individually and in groups, and asked them to perform certain tasks (Kuik, 2003; Renold, 2005; Thorne \& Luria, 1986). A researcher can be more confident about the reliability and validity of a result if different methods lead to the same result.

This review focused on studies that described sexual behaviors, emotions, and cognitions of children. Insight into what childhood sexual behavior can be expected and how children perceive this behavior, however, is not sufficient in order to decide how to react to these experiences. Knowledge of the long-term consequences of these events is also essential. Children with experiences that increase the likelihood of negative outcomes might need extra guidance, unlike those who display behaviors with no or positive longterm outcomes. In addition, research on the determinants and processes underlying sexual development is scarce. Reviewing studies on the determinants and outcomes of childhood non-abusive sexual experiences and finding methodologies to investigate these complex processes provide challenges for future studies.

Furthermore, this review is limited to studies that were conducted in Western societies: North America, Western Europe, Australia, or New Zealand. The sociocultural context in these countries affected the research questions that were formulated, the methodologies that were chosen, and the results of these studies. The findings of this review, therefore, cannot be generalized to non- Western societies. Future studies should expand our review to research of sexual development since 1980 in these societies, to gain insight into cross-cultural similarities and differences.

Finally, as sexual development is just one aspect of childhood development, research on this subject does not have to be, or perhaps should not be, separated from the study of other developmental areas. Interviews with children could cover a broad range of topics that are of interest to them, such as relationships with parents, school, friendships, and play. Being in love, touching, cuddling and kissing, and curiosity about their own and others' bodies could also be investigated during these interviews. Sexuality should be approached as an integrated, intrinsic part of general development, rather than treating it in isolation. Embedding sexual development into theoretical frameworks of general development (e.g., Bronfenbrenner's ecological systems theory; Bronfenbrenner \& Morris, 1998) could be helpful for this approach to childhood sexuality.

\section{REFERENCES}

Ballester, A. R., \& Gil, L. M. D. (2006). La sexualidad en niños de 9 a 14 años [Sexuality in children 9-14 years old]. Psicothema, 18, 25-30.

Bancroft, J. (Ed.). (2003). Sexual development in childhood. Bloomington, IN: Indiana University Press. Bancroft, J. (2009). Human sexuality and its problems. Edinburgh, Scotland: Elsevier.

Bancroft, J., Herbenick, D., \& Reynolds, M. (2003). Masturbation as a marker of sexual development. In J. Bancroft (Ed.), Sexual development in childhood (pp. 156-185). Bloomington, IN: Indiana University Press.

Berends, M. M., \& Caron, S. L. (1994). Children's understanding and knowledge of conception and birth: A developmental approach.

Journal of Sex Education and Therapy, 20, 18-29.

Berney, L. R., \& Blane, D. B. (1997). Collecting retrospective data: Accuracy of recall after 50 years judged against historical records. 
Graaf, H. de, Rademakers, J. The psychological measurement of childhood sexual development in Western societies: methodological challenges. Journal of Sex Research: 2011, 48(2), 118-129

Social Science \& Medicine, 45, 1519-1525.

Blair, J. (2000). Assessing protocols for child interviews. In A. A.

Stone, J. S. Turkkan, C. A. Bachrach, J. B. Jobe, H. S. Kurtzman \& V. S. Cain (Eds.), The science of selfreport: Implications for research and practice (pp. 161-174). Mahwah, NJ: Lawrence Erlbaum Associates, Inc.

Brilleslijper-Kater, S. N., \& Baartman, H. E. M. (2000). What do young children know about sex? Research on the knowledge of sexuality of children between the ages of 2 and 7 years. Child Abuse Review, 9 , 166-182.

Bronfenbrenner, U., \& Morris, P. A. (1998). The ecology of developmental processes. In D. William \& R. M. Lerner (Eds.), Handbook of child psychology: Volume 1: Theoretical models of human development (5th ed., pp. 993-1028). Hoboken, NJ: John Wiley \& Sons.

Campbell, D. T., \& Fiske, D. W. (1959). Convergent and discriminant validation by the multitraitmultimethod matrix. Psychological Bulletin, 56, 81-105.

Campbell, T. A., \& Campbell, D. E. (1986). Adolescent interest in human sexuality: The questions kids ask. Journal of Sex Education and Therapy, 12, 47-50.

Davies, S., Glaser, D., \& Kossof, R. (2000). Children's sexual play and behavior in pre-school settings: Staff's perceptions, reports and responses. Child Abuse \& Neglect, 24, 1329-1343.

De Graaf, H., \& Rademakers, J. (2006). Sexual behavior of prepubertal children. Journal of Psychology \& Human Sexuality, 18, 1-21.

De Graaf, H., \& Rademakers, J. (2009). "Seks in de groei": Update anno 2009 ["Sexually growing up": Update anno 2009]. Utrecht, The Netherlands: Rutgers Nisso Groep.

Finkelhor, D. (1981). Sex between siblings: Sex, incest, and aggression.

In L. L. Constantine \& F. M. Martinson (Eds.), Children and sex: New findings, new perspectives (pp. 129149). Boston, MA: Little, Brown.

Frayser, S. G. (1995). Defining normal childhood sexuality: An anthropological approach. Annual Review of Sex Research, 5, 173-217.

Friedrich, W. N. (2003). Studies of sexuality in nonabused children. In J. Bancroft (Ed.), Sexual development in childhood (pp. 107-120).

Bloomington, IN: Indiana University Press.

Friedrich, W. N., Fisher, J., Broughton, D., Houston, M., \& Shafran, C. R. (1998). Normative sexual behavior in children: A contemporary sample. Pediatrics, 101, e9.

Friedrich, W. N., Grambsch, P., Broughton, D., Kuiper, J., \& Beilke, R. L. (1991). Normative sexual behavior in children. Pediatrics, 88, 456-464.

Friedrich, W. N., Sandfort, T. G. M., Oostveen, J., \& Cohen-Kettenis, P. T. (2000). Cultural differences in sexual behavior: 2-6 year old Dutch and American children. Journal of Psychology \& Human Sexuality, 12, 117-129.

Galenson, E. (1990). Observation of early infantile sexual and erotic development. In M. E. Perry (Ed.), Handbook of sexology, Vol.

7: Childhood and adolescent sexology (pp. 169-178). Amsterdam, The Netherlands: Elsevier.

Goldman, R., \& Goldman, J. (1982). Children's sexual thinking: A comparative study of children aged 5 to 15 years in Australia, North America, Britain and Sweden. London, England: Routledge \& Kegan Paul.

Goldman, R., \& Goldman, J. (1988). Show me yours: What children think about sex. Victoria, Australia: Penguin.

Gordon, B. N., Schroeder, C. S., \& Abrams, J. M. (1990). Age and social-class differences in children's knowledge of sexuality.

Journal of Clinical Child Psychology, 1, 33-43.

Gundersen, B. H., Mela ${ }^{\circ}$ S, P. S., \& Ska ${ }^{\circ}$, J. E. (1981). Sexual behavior of preschool children: Teachers' observations. In L. L.

Constantine \& F. M. Martinson (Eds.), Children and sex: New findings, new perspectives (pp. 45-61). Boston, MA: Little, Brown.

Halstead, J. M., \& Waite, S. (2001). "Living in different worlds": Gender differences in the developing sexual values and attitudes of primary school children. Sex Education, 1, 59-76.

Hatfield, E., Schmitz, E., Cornelius, J., \& Rapson, R. L. (1988). Passionate love: How early does it begin? Journal of Psychology \& Human Sexuality, 1, 35-51.

Haugaard, J. J. (1996). Sexual behaviors between children: Professionals' opinions and undergraduates' recollections. Families in Society: The Journal of Contemporary Human Services, 77, 81-89.

Haugaard, J. J., \& Tilly, C. (1988). Characteristics predicting children's responses to sexual encounters with other children. Child Abuse \& Neglect, 12, 209-218.

Kaeser, F., DiSalvo, C., \& Moglia, R. (2000). Sexual behaviors of young children that occur in schools. Journal of Sex Education \& Therapy, 25, 277-285. 
Graaf, H. de, Rademakers, J. The psychological measurement of childhood sexual development in Western societies: methodological challenges. Journal of Sex Research: 2011, 48(2), 118-129

Kilpatrick, A. C. (1986). Some correlates of women's childhood sexual experiences: A retrospective study. Journal of Sex Research, 22, 221-242.

Kuik, S. (2003). Leaving childhood: Sexuality and how children become adolescents. Netherlands' Journal of Social Sciences, 39, 11-22.

Lamb, M. E., Hershkowitz, I., Orbach, Y., \& Esplin, P. W. (2008). Tell me what happened: Structured investigative interviews of child victims and witnesses. New York, NY: Wiley.

Lamb, S. (2004). Sexual tensions in girls' friendships. Feminism \& Psychology, 14, 376-382.

Lamb, S., \& Coakley, M. (1993). "Normal" childhood sexual play and games: Differentiating play from abuse. Child Abuse \& Neglect, 17, 515-526.

Larsson, I., \& Svedin, C. G. (2002a). Sexual experiences in childhood: Young adults' recollections. Archives of Sexual Behavior, 31, 263-273.

Larsson, I., \& Svedin, C. G. (2002b). Teachers' and parents' reports on 3- to 6-year-old children's sexual behavior-A comparison. Child Abuse \& Neglect, 26, 247-266.

Lindblad, F., Gustafsson, P. A., Larsson, I., \& Lundin, B. (1995).

Preschoolers' sexual behavior at daycare centers: An epidemiological study. Child Abuse \& Neglect, 19, 569-577.

Lopez Sanchez, F., Del Campo, A., \& Guijo, V. (2002). Prepubertal sexuality. Sexologies, 11, 49-58.

Martin, C., \& Ruble, D. N. (2010). Patterns of gender development.

Annual Review of Psychology, 61, 353-381.

Nelson, J. A. (1986). Incest: Self-report findings from a nonclinical sample. Journal of Sex Research, 22, 463-477.

Newcombe, N. S., Bullock Drummey, A., Fox, N. A., Lie, E., \& Ottinger-Alberts, W. (2000). Remembering early childhood: How much, how, and why (or why not). Current Directions in Psychological Science, 9, 55-58.

Okami, P., Olmstead, R., \& Abramson, P. R. (1997). Sexual experiences in early childhood: 18-year longitudinal data from the UCLA Family Lifestyles Project. Journal of Sex Research, 34, 339-347.

Oostveen, J. M. E., Meulmeester, J. F., \& Cohen-Kettenis, P. T.

(1994). Seksueel gedrag van kleuters [Preschoolers' sexual behavior].

Nederlands Tijdschrift voor Geneeskunde, 138, 2200-2204.

O'Sullivan, L. F., \& Meyer-Bahlberg, H. F. L. (2003). African American and Latina inner-city girls' reports of romantic and sexual development. Journal of Social and Personal Relationships, 20, 221-238.

Ott, M. A., \& Pfeiffer, E. J. (2009). "That's nasty" to curiosity: Early adolescent cognitions about sexual abstinence. Journal of Adolescent Health, 44, 575-581.

Paikoff, R. L. (1995). Early heterosexual debut: Situations of sexual possibility during the transition of adolescence. American Journal of Orthopsychiatry, 65, 389-401.

Phipps-Yonas, S., Yonas, A., Turner, M., \& Kauper, M. (1993).

Sexuality in early childhood: The observations and opinions of family daycare providers. CURA Reporter, 23(2), 1-5.

Piaget, J., \& Inhelder, B. (1969). The psychology of the child. New York: Basic Books.

Rademakers, J., Laan, M., \& Straver, C. J. (2003). Body awareness and physical intimacy: An exploratory study. In J. Bancroft (Ed.), Sexual development in childhood (pp. 121-125). Bloomington, IN: Indiana University Press.

Renold, E. (2005). Girls, boys and junior sexualities: Exploring children's gender and sexual relations in the primary school. London, England: Routledge=Falmer.

Reynolds, M. A., Herbenick, D. L., \& Bancroft, J. H. (2003). The nature of childhood sexual experiences: Two studies 50 years apart. In J. Bancroft (Ed.), Sexual development in childhood (pp. 134-155). Bloomington, IN: Indiana University Press.

Rosenfeld, A., Bailey, R., Siegel, B., \& Bailey, G. (1986). Determining incestuous contact between parent and child: Frequency of children touching parents' genitals in a nonclinical population.

Journal of American Academy of Child Psychiatry, 25, 481-484.

Sandfort, T. G. M., \& Cohen-Kettenis, P. T. (2000). Sexual behavior in Dutch and Belgian children as observed by their mothers. Journal of Psychology \& Human Sexuality, 12, 105-115.

Sandnabba, N., Santtila, P., Wanna" s, M., \& Krook, K. (2003). Age and gender specific sexual behaviors in children. Child Abuse \& Neglect, 27, 579-605.

Schoentjes, E., Deboutte, D., \& Friedrich, W. (1999). Child Sexual Behavior Inventory: A Dutch-speaking normative sample.

Pediatrics, 104, 885-893.

Schuhrke, B. (2000). Young children's curiosity about other people's genitals. Journal of Psychology \& Human Sexuality, 12, 27-48. 
Graaf, H. de, Rademakers, J. The psychological measurement of childhood sexual development in Western societies: methodological challenges. Journal of Sex Research: 2011, 48(2), 118-129

Thigpen, J. W. (2009). Early sexual behavior in a sample of lowincome, African American children. Journal of Sex Research, 46, 67-79.

Thorne, B., \& Luria, Z. (1986). Sexuality and gender in children's daily worlds. Social Problems, 33, 176190.

Volbert, R. (2000). Sexual knowledge of preschool children. Journal of Psychology \& Human Sexuality, 12, 5-26.

\section{[TABLES]}

Table 1. Characteristics of Studies Reviewed

\begin{tabular}{|c|c|c|c|}
\hline Study & Topic & Sample & Method \\
\hline Ballester \& Gil (2006) & Sexual behavior, attitudes, and feelings & 243 boys and 227 girls, aged $9-14$ & Survey \\
\hline Bancroft, Herbenick, \& Reynolds (2003) & $\begin{array}{l}\text { Masturbation and orgasm, pre- and } \\
\text { post-pubertal }\end{array}$ & $\begin{array}{l}134 \text { men and } 149 \text { women, college students, } \\
\text { aged } 18-22\end{array}$ & Retrospective survey \\
\hline Berends \& Caron (1994) & Knowledge of conception and birth & $\begin{array}{l}26 \text { boys and } 14 \text { girls, aged } 5-12 \text {, and their } \\
\text { parents }\end{array}$ & Interviews, supported by drawings \\
\hline Brilleslijper-Kater \& Baartman (2000) & Knowledge of sexuality & $\begin{array}{l}32 \text { boys and } 31 \text { girls, Dutch, aged } 2-6 \text {, and } \\
\text { their parents }\end{array}$ & Interviews, supported by drawings \\
\hline T. A. Campbell \& Campbell (1986) & Questions about sexuality-related topics & $\begin{array}{l}\text { High school students, aged 11-14, total } \\
\text { number and gender distribution } \\
\text { unknown }\end{array}$ & $\begin{array}{l}\text { Categorization of } 874 \text { questions, collected } \\
\text { in the classroom }\end{array}$ \\
\hline Davies, Glaser, \& Kossof (2000) & $\begin{array}{l}\text { Sexual behavior and responses from } \\
\text { preschool staff }\end{array}$ & $\begin{array}{l}58 \text { preschool staff for children aged } 2-5 \text {, } \\
\text { gender of children unknown }\end{array}$ & Observations by day care personnel \\
\hline Finkelhor (1981) & $\begin{array}{l}\text { Sexual experiences between siblings in } \\
\text { childhood }\end{array}$ & $\begin{array}{l}796 \text { college students, two-thirds women, } \\
17 \% \text { older than } 24\end{array}$ & Retrospective survey \\
\hline $\begin{array}{l}\text { Friedrich, Grambsch, Broughton, \& } \\
\text { Kuiper (1991) }\end{array}$ & Sexual behavior & 458 boys and 422 girls, aged $2-12$ & Observations by mothers \\
\hline $\begin{array}{l}\text { Friedrich, Fisher, Broughton, Houston, \& } \\
\text { Shafran (1998) }\end{array}$ & Sexual behavior & 560 boys and 553 girls, aged $2-12$ & Observations by mothers \\
\hline $\begin{array}{l}\text { Friedrich, Sandfort, Oostveen, \& } \\
\text { Cohen-Kettenis (2000) }\end{array}$ & $\begin{array}{l}\text { Differences in sexual behavior between the } \\
\text { Netherlands and the United States }\end{array}$ & $\begin{array}{l}807 \text { boys and } 656 \text { girls, Dutch and } \\
\text { American, aged } 2-6\end{array}$ & Observations by mothers \\
\hline Galenson (1990) & Masturbation & $\begin{array}{l}70 \text { boys and girls, aged } 0-2 \text {, gender } \\
\text { distribution unknown }\end{array}$ & Observations by researcher \\
\hline Goldman \& Goldman (1982) & $\begin{array}{l}\text { Knowledge of sexuality and sources of } \\
\text { information }\end{array}$ & $\begin{array}{l}419 \text { boys and } 419 \text { girls, aged } 5-15 \text {, } \\
\text { American, English, Swedish, and } \\
\text { Australian }\end{array}$ & Interviews \\
\hline Goldman \& Goldman (1988) & $\begin{array}{l}\text { Sexual behavior during childhood and } \\
\text { adolescence }\end{array}$ & $\begin{array}{l}1,000 \text { Australian college students, aged } \\
18-23 \text {, gender distribution unknown }\end{array}$ & Retrospective survey \\
\hline Gordon, Schroeder, \& Abrams (1990) & Knowledge of sexuality & 74 boys and 56 girls, aged $2-7$ & Interviews, supported by drawings \\
\hline Gundersen, Melås, \& Skår (1981) & Sexual behavior & $\begin{array}{l}60 \text { preschool teachers of children aged } \\
3-7 \text {, gender of children unknown }\end{array}$ & Observations by preschool teachers \\
\hline Halstead \& Waite (2001) & Sexual values and attitudes & $\begin{array}{l}35 \text { socially disadvantaged children, aged } \\
9-10 \text {, gender distribution unknown }\end{array}$ & Focus groups \\
\hline $\begin{array}{l}\text { Hatfield, Schmitz, Cornelius, \& Rapson } \\
\text { (1988) }\end{array}$ & Feelings of "passionate love" & $\begin{array}{l}114 \text { boys and } 122 \text { girls, aged } 4-18 \\
\text { Hawaiian }\end{array}$ & Interviews \\
\hline Haugaard (1996) & $\begin{array}{l}\text { Sexual encounters between children and } \\
\text { responses from professionals }\end{array}$ & $\begin{array}{l}199 \text { men and } 465 \text { women, college students, } \\
\text { mean aged } 20 \text {, and } 337 \text { experts }\end{array}$ & Retrospective survey \\
\hline Haugaard \& Tilly (1988) & $\begin{array}{l}\text { Sexual encounters between children before } \\
\text { age } 13 \text { and accompanying feelings }\end{array}$ & $\begin{array}{l}425 \text { men and } 664 \text { women, college students, } \\
\text { mean aged } 19.2\end{array}$ & Retrospective survey \\
\hline Kaeser, DiSalvo, \& Moglia (2000) & Sexual behavior & 360 boys and 343 girls, aged $5-7$ & Diary observations by preschool teachers \\
\hline Kuik (2003) & Talking about sex and romance & 19 girls and 11 boys, about 11 years old & $\begin{array}{l}\text { Observations by researcher, interviews, } \\
\text { surveys, drawings, and drama tasks }\end{array}$ \\
\hline
\end{tabular}


Graaf, H. de, Rademakers, J. The psychological measurement of childhood sexual development in Western societies: methodological challenges. Journal of Sex Research: 2011, 48(2), 118-129

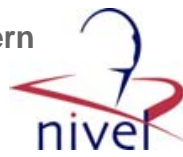

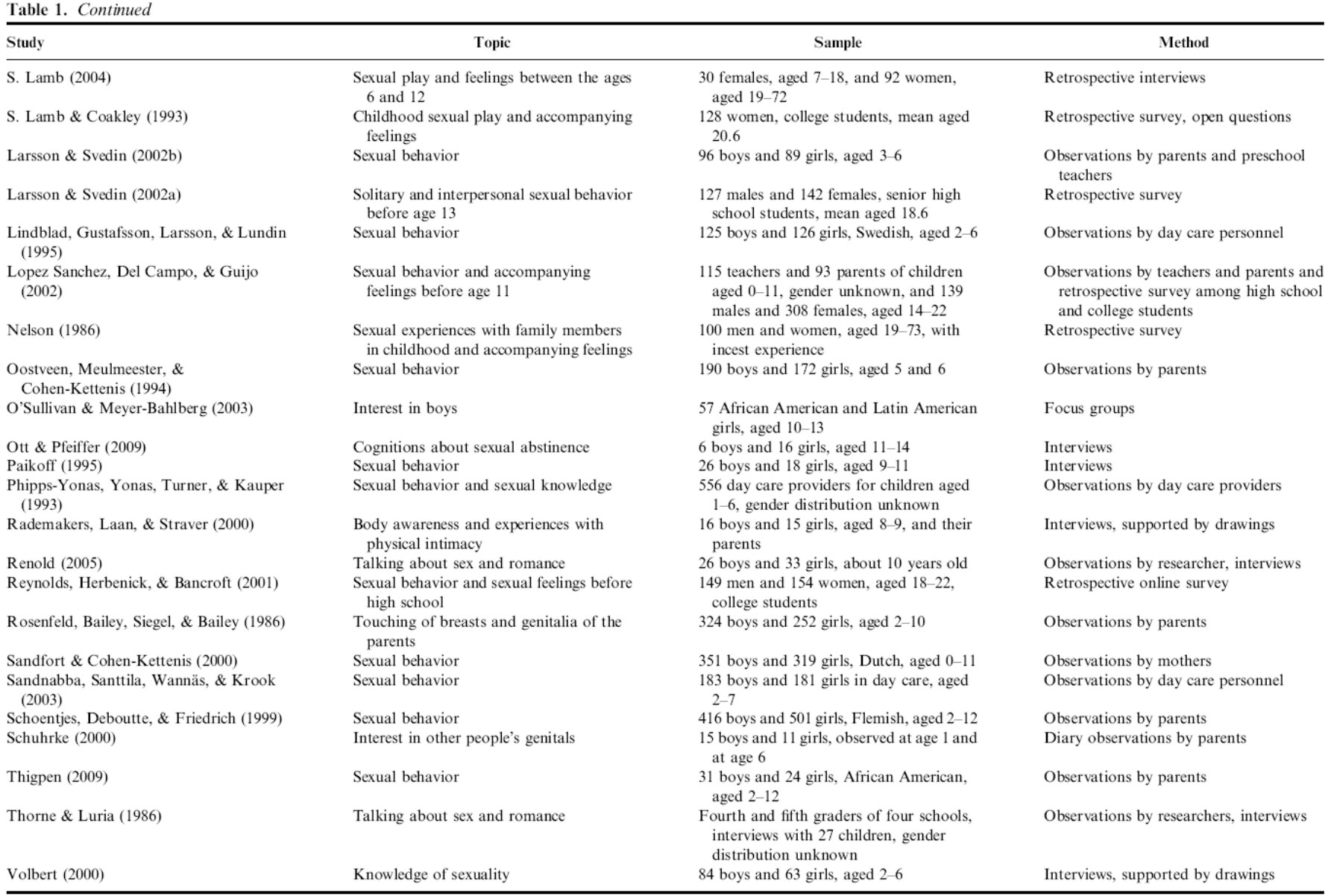

Table 2. Methods Used by the Studies Included in This Review

Method

No.

Observations

Intermediary reports (parents or teachers) in survey

Intermediary reports (parents or teachers) in interview 2

Intermediary reports (parents or teachers) in diaries 2

Direct observations by researchers 1

Observations and interviews by researchers 3

Retrospective reports of adolescents or adults

$\begin{array}{ll}\text { Reported in survey } & 10\end{array}$

Reported in interview 1

Direct study of children

Interviews 10

Collection of questions 1

Survey 1

Total 44 
Graaf, H. de, Rademakers, J. The psychological measurement of childhood sexual development in Western societies: methodological challenges. Journal of Sex Research: 2011, 48(2), 118-129

Table 3. Advantages and Limitations of Traditional Methods

\begin{tabular}{|c|c|c|}
\hline Method & Advantages & Limitations \\
\hline \multirow{2}{*}{$\begin{array}{l}\text { Observations by } \\
\text { researchers }\end{array}$} & Suitable for all age groups, even newborns & Only overtly displayed behaviors can be observed \\
\hline & Possibility of interrater reliability & $\begin{array}{l}\text { Influence of the researcher's perspective cannot be } \\
\text { ruled out }\end{array}$ \\
\hline $\begin{array}{l}\text { Observations by } \\
\text { intermediaries }\end{array}$ & $\begin{array}{l}\text { Less time-consuming, therefore easier to obtain } \\
\text { information from larger samples }\end{array}$ & $\begin{array}{l}\text { Influence of the intermediary's perspective probably } \\
\text { substantial }\end{array}$ \\
\hline \multirow[t]{3}{*}{ Retrospective research } & $\begin{array}{l}\text { Cognitive abilities have sufficiently developed to answer } \\
\text { questions }\end{array}$ & Reports can be distorted by memory \\
\hline & Possibility to investigate cognitions or emotions & Experiences are remembered from an adult perspective \\
\hline & Parental consent not (always) required & \\
\hline \multirow[t]{2}{*}{ Surveys among children } & Possibility to gain insight into the child's perspective & $\begin{array}{l}\text { Research instrument is restricted (e.g., in terms of } \\
\text { complexity) }\end{array}$ \\
\hline & Possibility to investigate cognitions or emotions & $\begin{array}{l}\text { Difficulty of developing an instrument that is both } \\
\text { reliable and valid }\end{array}$ \\
\hline \multirow[t]{3}{*}{ Interviews with children } & Validity of research instrument higher & $\begin{array}{l}\text { Research instrument is restricted (e.g., in terms of } \\
\text { complexity) }\end{array}$ \\
\hline & $\begin{array}{l}\text { Possibility to expand method with visual material } \\
\text { (e.g., drawings) }\end{array}$ & $\begin{array}{l}\text { Researchers encounter resistance from parents and } \\
\text { other educators }\end{array}$ \\
\hline & & Time-consuming \\
\hline
\end{tabular}

